\title{
PENINGKATAN KEMAMPUAN ASERTIF DAN PENURUNAN PERSEPSI MELALUI ASSERTIVE TRAINING THERAPY PADA SUAMI DENGAN RISIKO KDRT
}

\author{
Nuniek Setyo Wardani ${ }^{1,2 *}$, Budi Anna Keliat ${ }^{3}$, Tuti Nuraini ${ }^{3}$ \\ 1. Sekolah Tinggi Ilmu Keperawatan Muhammadiyah Pontianak, Pontianak 78124, Indonesia \\ 2. Program Studi Magister Ilmu Keperawatan Universitas Indonesia, Depok 16424, Indonesia \\ 3. Fakultas Ilmu Keperawatan Universitas Indonesia, Depok 16424, Indonesia \\ *Email: sweetnoens@gmail.com
}

\begin{abstract}
Abstrak
Peningkatan masalah dalam rumah tangga dengan kurangnya pemecahan masalah yang baik memicu terjadinya kekerasan dalam rumah tangga, baik pada usia pernikahan muda maupun tua. Tujuan penelitian ini melihat pengaruh assertive training therapy (ATT) terhadap kemampuan asertif dan persepsi istri terhadap risiko kekerasan dalam rumah tangga suami. Desain penelitian Quasi Experimental Pre-Post Test With Control Group, dengan sampel 60 orang istri dengan resiko kekerasan dalam rumah tangga. Hasil menunjukkan ATT berpengaruh meningkatkan kemampuan asertif istri sebesar $86,9 \%$ dan persepsi istri terhadap risiko kekerasan menurun 71,3\%. Istri yang diberi ATT mempunyai kemampuan asertif meningkat secara bermakna dan persepsi istri terhadap risiko kekerasan dalam rumah tangga suami lebih rendah dibandingkan yang tidak diberikan ATT. Assertive Training Therapy direkomendasikan untuk istri dengan resiko kekerasan dalam rumah tangga.
\end{abstract}

Kata kunci: assertive training therapy, kemampuan asertif istri, persepsi istri terhadap perilaku power dan kontrol suami, kekerasan dalam rumah tangga

\begin{abstract}
Increase in domestic problems with a lack of good problem solving trigger domestic violence, both young and old age marriage. Purpose of the study was to discover the effect of assertive training therapy (ATT) to assertive ability and wives perception to husband with risk of domestic violence. The study's design was Quasi Experimental Pre-Post Test With Control Group, with 60 wives with the risk of domestic violence. Result showed that the ATT effect increases the ability of assertive wife of $86,9 \%$ and the wife's perception of the risk of domestic violence by husbands were decreased $71.3 \%$. ATT has a wife who is given a Assertive skills increased significantly and the wife 's perception of the risk of domestic violence is lower than the husband who is not given ATT. Therapy Training assertive recommended to his wife with the risk of domestic violence.
\end{abstract}

Keywords: assertive training therapy, wife's assertive ability, wife's perception of power and control the behavior of husbands, domestic violence

\section{Pendahuluan}

Perkawinan adalah suatu ikatan yang terjalin antara pria dan wanita sebagai suami istri berdasarkan hukum (UU), hukum agama atau adat istiadat yang berlaku. Strong, Devault, dan Cohen (2008), yang mengungkapkan bahwa perkawinan adalah suatu hubungan yang resmi antara dua orang, umumnya pria dan wanita, yang berbeda jenis kelamin, bekerja sama dalam menunjang perekonomian, dan dapat memberikan keturunan, baik melalui adopsi maupun anak kandung. Sehingga dapat disimpulkan bahwa hubungan keluarga yang terjalin antara suami dan istri didasarkan oleh ikatan perkawinan yang terjadi diantara keduanya.

Hubungan perkawinan tersebut hanya akan terjadi bila adanya saling ketertarikan antara pria dan wanita dimana pada prosesnya memiliki dua macam aspek, yaitu aspek biologis dan afeksional. Apabila tidak adanya saling ketertarikan antara pria dan wanita, maka hubungan perkawinan tidak akan terjadi. Dengan terbentuknya hubungan perkawinan, maka terbentuklah sebuah keluarga yang didalamnya terdapat kebahagiaan, cinta, dan kasih sayang. 
Masalah-masalah yang dihadapi keluarga umumnya berhubungan dengan masalah dalam mendidik anak (Strong, 2008). Masalah ini dapat timbul bila ibu yang memegang peran sebagai pendidik dalam keluarga tidak mampu untuk menjalankan perannya dan memicu timbulnya konflik antara suami dan istri.

Selain masalah dalam mendidik anak, DeGenova (2008) menyatakan bahwa masalah yang dihadapi keluarga adalah masalah mengenai; perekonomian, keluarga dengan tingkat ekonomi yang rendah dapat menyebabkan tidak terpenuhinya kebutuhan keluarga; komunikasi, sangat berperan penting didalam keluarga karena dengan komunikasi keluarga dapat menyampaikan perasaan, dan keinginan. Beberapa keluarga yang tidak mampu beradaptasi terhadap permasalahan yang muncul diakibatkan fungsi dalam keluarga tidak berjalan dengan semestinya sehingga akan mengakibatkan konflik yang berkepanjangan. Konflik yang berkepanjangan ini pula yang akhirnya akan menyebabkan terjadinya kekerasan dalam rumah tangga.

Kekerasan dalam rumah tangga adalah perbuatan terhadap seseorang yang berakibat timbulnya kesengsaraan atau penderitaan secara fisik, seksual, psikologis, dan/ atau penelantaran rumah tangga termasuk ancaman untuk melakukan perbuatan, pemaksaan, atau perampasan kemerdekaan secara melawan hukum dalam lingkup rumah tangga (UU No. 23 tahun 2004). Menurut Cherlin (2002), yang menyatakan bahwa kekerasan dalam rumah tangga adalah tindakan seseorang yang dapat mengakibatkan timbulnya cedera, baik secara fisik, dan seksual. Jadi dapat dikatakan kekerasan dalam rumah tangga (KDRT) adalah suatu perilaku kekerasan atau perilaku pengontrolan yang dilakukan seseorang secara sengaja oleh orang yang telah dikenal dekat oleh korban, baik yang tinggal maupun tidak berada dalam rumah yang sama.

Data WHO (2002), menyebutkan bahwa angka kejadian kekerasan dalam rumah tangga antara 40 hingga 60 persen perempuan yang meninggal karena pembunuhan, secara umum dilakukan oleh mantan atau pasangannya sendiri. Catatan Komnas Perempuan menyatakan bahwa jumlah kekerasan terhadap perempuan terus meningkat dari tahun 2001 hingga 2008. Bahkan, dari tahun 2007 ke 2008 jumlahnya meningkat dua kali lipat. Pada tahun 2006 sampai 2007, data yang didapat dari Mitra Perempuan menyatakan bahwa di wilayah Jakarta dan Bogor terdapat 606 kasus kekerasan dalam rumah tangga (Dharmono \& Diatri, 2008).

Kejadian kekerasan dalam rumah tangga (KDRT) jika dilihat dari usia perkawinan, usia yang rentan terjadi kekerasan dalam rumah tangga (KDRT) adalah pada usia perkawinan 1 sampai 5 tahun pertama dan menikah pada usia muda kurang dari 20 tahun. Prosentase yang ditunjukan terjadinya kekerasan dalam rumah tangga (KDRT) pada usia perkawinan ini adalah sebesar 21,544\%. Kemudian diikuti oleh usia perkawinan 10 sampai 15 tahun sebanyak $21,435 \%$, usia perkawinan lebih dari 15 tahun sebesar $21,223 \%$ dan usia perkawinan 5 sampai 10 tahun sebesar 20,828\% (Wiyarsi, Salirawati, \& Sulistiyowati, 2010). Berdasarkan data tersebut, dapat disimpulkan bahwa usia perkawinan pada masa 5 tahun pertama merupakan masa dimana usia perkawinan yang rawan terjadinya konflik dalam rumah tangga sehingga menimbulkan terjadinya kekerasan dalam rumah tangga (KDRT).

Upaya penyelesaian masalah keluarga yang sifatnya sensitif tidak cukup diselesaikan dengan jalur hukum saja, akan tetapi keluarga membutuhkan suatu terapi untuk menyelesaikan masalah yang sifatnya tidak mengancam. Hamid (2009), menyatakan bahwa ada beberapa terapi yang dapat diberikan untuk keluarga dengan tindak kekerasan dalam rumah tangga seperti terapi keluarga, terapi kelompok, dan terapi pendidikan. Terapi yang diberikan bertujuan untuk meningkatkan keamanan fisik, terjadi peningkatan harga diri, mengurangi perasaan tidak berdaya, menghilangkan perasaan putus asa, dan mencegah terjadinya bunuh diri, serta isolasi sosial. 
Stuart dan McDonald (2009), menyebutkan bahwa upaya pencegahan yang dilakukan adalah bentuk intervensi keperawatan yang memiliki peran penting dalam mencegah terjadinya kekerasan dalam rumah tangga. Upaya yang diberikan meliputi pendidikan masyarakat, pendeteksian faktor risiko adanya kekerasan dalam rumah tangga, serta mencegah masalah yang lebih kompleks dari terjadinya abuse.

Pencegahan yang dilakukan yaitu mencakup: (1) pencegahan primer yang dilakukan dengan cara memberikan penguatan pada individu dan keluarga dengan membangun koping yang efektif dalam menghadapi stres dan menyelesaikan masalah tanpa menggunakan kekerasan; (2) Pencegahan sekunder, dengan cara mengidentifikasi keluarga dengan risiko kekerasan, penelantaran, atau eksploitasi terhadap anggota keluarga, serta melakukan deteksi dini terhadap keluarga yang mulai menggunakan kekerasan; (3) Pencegahan tersier, dilakukan dengan cara menghentikan tindak kekerasan yang terjadi bekerjasama dengan badan hukum yang berwenang untuk menangani kasus kekerasan.

Townsend (2009) menuturkan bahwa untuk mengatasi perilaku yang muncul sebagai dampak dari tindak kekerasan dalam rumah tangga dapat diberikan terapi asertif atau assertive training therapy. Terapi asertif, atau lebih dikenal dengan assertive training therapy adalah suatu terapi modaliltas keperawatan dalam bentuk terapi kelompok (terapi tingkah laku), klien belajar mengungkapkan rasa marah secara tepat atau asertif sehingga pasien mampu untuk berhubungan dengan orang lain, mampu menyatakan; apa yang diinginkannya, apa yang disukainya, dan apa yang ingin dia kerjakan dan kemampuan untuk membuat seseorang merasa tidak risih berbicara tentang dirinya sendiri.

\section{Metode}

Penelitian ini merupakan penelitian kuantitatif dengan menggunakan desain penelitian "Quasi
Experimental Pre-Post Test With Control Group", yaitu peneliti memberikan perlakuan terhadap variabel independen, kemudian mengukur pengaruh perlakuan tersebut pada variabel dependen (Notoatmodjo, 2010). Perlakuan yang diberikan adalah Assertive Training Therapy (ATT) pada istri dalam keluarga dengan risiko kekerasan dalam rumah tangga. Tehnik pengambilan sampel yaitu menggunakan metode Total Sampling.

Instrumen penelitian yang digunakan adalah instrumen yang telah dikembangkan oleh Novianti (2010) dan dimodifikasi sesuai dengan responden penelitian yaitu istri pada keluarga dengan risiko perilaku kekerasan. Instrumen yang digunakan adalah lembar kuesioner A (Data Demografi Keluarga), B (Kemampuan Asertif, 20 pertanyaan) dan C (Persepsi Istri terhadap Perilaku Power dan Kontrol Suami, 15 pertanyaan).

Penelitian ini dilakukan di kelurahan Katulampa Kota Bogor, khususnya untuk wilayah yang didominasi oleh tingkat ekonomi rendah, usia pernikahan muda dan penduduk padat yang ada di 3 (tiga) RW Kelurahan Katulampa Kota Bogor, Jawa Barat. Pengumpulan data pre-test untuk tiap istri pada kelompok yang mendapat therapy group (TG) dan Assertive Training Therapy (ATT) dilakukan sebelum sesi I, yaitu pada tanggal 16 Mei 2011.

Sedangkan post-test dilakukan setelah sesi VI selesai untuk tiap responden. Pengumpulan data pre-test untuk kelompok yang hanya mendapatkan therapy group (TG) dilakukan pada 06 Juni 2011 secara serempak di kelurahan Katulampa dan data post-test dilakukan secara serempak juga pada tanggal 11 Juni 2011.

Analisis data diolah dengan program statistik meliputi analisis univariat berupa sentral tendensi dan distribusi frekuensi. Analisis bivariat menggunakan independent t-test, dependent t-test (Paired t-test) dan chi square. Analisis multivariat menggunakan uji regresi linear ganda. 
Grafik 1. Kemampuan Asertif dan Persepsi Istri setelah Dilakukan Assertive Training Therapy

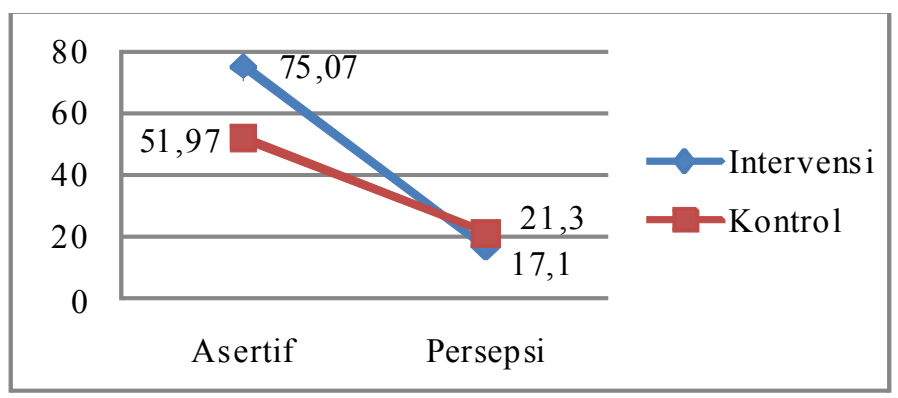

\section{Hasil}

Peningkatan kemampuan asertif istri setelah dilakukan terapi spesialis Assertive Training Therapy (ATT) pada kelompok intervensi mengalami peningkatan dimana sebelum intervensi dilakukan, kemampuan asertif istri berada pada kategori rendah-sedang. Setelah dilakukan intervensi, kemampuan asertif istri tersebut meningkat menjadi kategori tinggi dan secara statistik peningkatan tersebut bermakna setelah dilakukan intervensi Assertive Training Therapy (ATT) (lihat pada grafik 1).

\section{Pembahasan}

Perbandingan kemampuan asertif istri untuk mencegah kekerasan dalam rumah tangga antar kelompok yang mendapat dan yang tidak mendapat Assertive Training Therapy (ATT) menunjukkan peningkatan kemampuan asertif istri terdapat perbedaan yang signifikan kemampuan asertif istri antara kelompok yang dilakukan Assertive Training Therapy (ATT) dibanding kelompok yang tidak dilakukan Assertive Training Therapy (ATT). Hal tersebut menunjukkan bahwa kemampuan asertif istri dalam mencegah terjadinya kekerasan dalam rumah tangga dapat meningkat melalui pemberian Assertive Training Therapy (ATT).

Kemampuan asertif pada istri adalah suatu tindakan yang dilakukan dalam mengungkapkan ekspresi secara jujur, nyaman, dan tanpa adanya kecemasan terhadap orang lain terutama dengan pasangannya (Sadock \& Sadock, 2005). Menurut Townsend (2009), bahwa perilaku asertif adalah perilaku yang meningkatkan kualitas hubungan antar manusia, memungkinkan untuk bertindak dengan cara yang terbaik, membuat perasaan lebih baik tanpa adanya rasa cemas, mengekspresikan perasaan secara jujur dan nyaman, dan dapat melaksanakan hak pribadi tanpa menyangkal hak orang lain. Assertive Training Therapy (ATT) bertujuan membantu merubah persepsi untuk meningkatkan kemampuan asertif individu, mengekspresikan emosi, dan untuk membangun kepercayaan diri seseorang (Alberti, \& Emmons, 2001 dalam Lin, et al., 2008).

Indikasi Assertive Training Therapy adalah untuk melatih klien yang mengalami kesulitan untuk menyatakan diri bahwa tindakannya adalah layak atau benar. Latihan ini terutama berguna, diantaranya untuk membantu individu yang tidak mampu mengungkapkan perasaan tersinggung, kesulitan menyatakan tidak, merasa tertekan karena dominansi orang lain (Alberti \& Emmons, 2001 dalam Townsend, 2009). Komunikasi yang asertif akan membantu seseorang untuk saling menghargai, sehingga mampu berbicara dan percaya diri. Cara berkomunikasi seperti ini akan juga mampu membantu seseorang untuk menyelesaikan konflik dengan orang lain (Videbeck, 2010).

Hasil penelitian ini menunjukkan bahwa tidak adanya pengaruh atau kontribusi karakteristik keluarga terhadap kemampuan asertif istri dalam mencegah kekerasan dalam rumah tangga. 
Hal tersebut membuktikan bahwa kemampuan asertif istri dalam mencegah kekerasan dalam rumah tangga dapat dilatih dengan intervensi yang baik salah satunya adalah Assertive Training Therapy (ATT).

Stuart dan Laraia (2005) menyatakan bahwa usia berhubungan dengan pengalaman seseorang dalam menghadapi berbagai macam stressor, kemampuan memanfaatkan sumber dukungan dan keterampilan dalam mekanisme koping. Dapat disimpulkan, bahwa usia tersebut diatas sudah mampu untuk memilih kebutuhan dasarnya secara baik dan dapat melakukan tindakan yang dapat memperbaiki kondisi dirinya.

Pendidikan menjadi salah satu tolok ukur kemampuan seseorang dalam berinteraksi dengan orang lain secara efektif (Stuart \& Laraia, 2005). Hal ini bertentangan dengan hasil penelitian yang dilakukan oleh peneliti. Selain itu, Hawari (2001), menyebutkan bahwa masalah pekerjaan merupakan sumber stres pada diri seseorang yang bila tidak dapat diatasi yang bersangkutan dapat jatuh sakit.

\section{Kesimpulan}

Karakteristik keluarga tidak mempengaruhi kemampuan asertif dan persepsi istri terhadap perilaku power dan kontrol suami dengan risiko kekerasan dalam rumah tangga. Terapi spesialis Assertive Training Therapy (ATT) meningkatkan kemampuan asertif secara bermakna pada kelompok intervensi dan menurunkan persepsi istri terhadap perilaku power dan kontrol suami. Peluang pengaruh Assertive Training Therapy (ATT) sebesar $87 \%$ terhadap kemampuan asertif istri dan $72 \%$ terhadap persepsi istri terhadap perilaku power dan kontrol suami.

Puskesmas hendaknya memfasilitasi program lanjutan terapi spesialis keperawatan keluarga berbasis komunitas, khususnya pada keluarga dengan risiko kekerasan dalam rumah tangga yang telah diberikan Assertive Training Therapy
(ATT) dengan menggunakan terapi generalis. Selain itu juga perlu adanya pelatihan lebih dalam kepada kader kesehatan mengenai cara pencegahan kekerasan dalam rumah tangga untuk keluarga yang memiliki risiko kekerasan dalam rumah tangga.

Perawat spesialis jiwa hendaknya lebih aktif dalam menerapkan asuhan keperawatan spesialis Assertive Training Therapy (ATT) setelah mendapatkan terapi generalis pada keluarga dengan risiko kekerasan dalam rumah tangga. Selain itu, diharapkan adanya perawat spesialis jiwa yang berada di dinas kesehatan sebagai pemberi konseling dalam mencegah risiko kekerasan dalam rumah tangga. Sebagai dasar pentingnya penempatan perawat spesialis jiwa di tatanan pelayanan kesehatan jiwa dengan kompetensi yang dimiliki.

Perlu dilakukan penelitian lanjutan dengan desain penelitian lain untuk melihat Pengaruh Assertive Training Therapy (ATT) terhadap Kemampuan Asertif dan Persepsi Istri terhadap perilaku power dan kontrol pada pasangan suami istri dengan risiko Kekerasan Dalam Rumah Tangga dalam jangka waktu yang lama agar dapat diketahui pengaruh ATT terhadap kemampuan asertif dan persepsi pasangan suami istri setelah pemberian terapi. Diharapkan agar pada penelitian berikutnya, kemampuan asertif dan persepsi pasangan suami istri dengan risiko kekerasan dalam rumah tangga dapat meningkat dalam upaya pencegahan kekerasan dalam rumah tangga (DN, AY, EF).

\section{Referensi}

Cherlin, A.J. (2002). Public and private families: An introduction (3rd Ed.). New York: McGrawHill.

DeGenova, M.K. (2008). Intimate relationships marriage and families (7th Ed.). New York: Graw Hill.

Dharmono, S., \& Diatri, H. (2008). Kekerasan dalam rumah tangga dan dampaknya terhadap kesehatan jiwa. Jakarta: Balai Penerbit FK-UI. 
Hamid, A.Y.S. (2009). Bunga rampai asuhan keperawatan kesehatan jiwa. Jakarta: Penerbit EGC.

Hawari, D. (2009). Penyiksaan fisik dan mental dalam rumah tangga. Jakarta: Balai Penerbit FK-UI.

Lin, Y.R., Wu, M.H., Yang, C.I., Chen, T.H., Hsu, C.C., Chang, Y.C., Tzeng, W.C., Chou, Y.H., \& Chou, K.R. (2008). Evaluation of assertiveness training for psychiatric patient. Journal of Clinical Nursing, 17 (21), 2875 -2883. DOI: 10.1111/j.1365-2702.2008.02343.x.

Notoatmodjo, S. (2010). Metodologi penelitian kesehatan (edisi revisi). Jakarta: Rineka Cipta.

Novianti, E. (2010). Pengaruh assetiveness training dalam mengontrol emosi anak usia sekolah di Kelurahan Jaya Bogor (Thesis, Program Pascasarjana FIK UI). Depok: FIK-UI.

Sadock, B.J., \& Sadock, V.A. (2005). Kaplan and Sadock's comprehensive textbook of psychiatry (8th Ed.). Philadelphia: Lippincott Williams \& Wilkin's.

Strong, B., Devault, C., \& Cohen T. F. (2008). The marriage and family experience: Intimate relationship in a changing society (10th Ed.). United States: Cengage Learning, Inc.
Stuart, G.W., \& Mc Donald, S.F. (2009). Virtual clinical excurtions psychiatric for principles and practice of psychiatric nursing (9th Ed.). San Diego: Mosby Elsevier.

Stuart, G.W., \& Laraia. (2009). Principles and practice of psychiatric nursing (9th Ed.). St. Louis: Mosby.

Townsend, M.C. (2009). Psychiatric mental health nursing: Concepts of care in evidence-based parctice. Philadelphia: F.A. Davis Company.

Undang-Undang No. 23 tahun 2004. (2004). Tentang kekerasan dalam rumah tangga. Diperoleh dari http://lbh.apik.or.id.diakses.

Videbeck, S.L. (2010). Psychiatric-mental health nursing. Philadelphia: Lippincott Williams \& Wilkins

Wiyarsi, Salirawati, \& Sulistiyowati. (2010). Survei kekerasan dalam rumah tangga pada wanita karir di DIY. Diperoleh dari http//eprints.uny.ac.id.

WHO. (2002). Violence and health fact sheet no. 239. Diperoleh dari http://www.who.int/ mediacentre/factsheets/fs239/en/. 